\title{
The Influence Of Operational Cost On The Bank's Profitability And The Welfare Of Its Clients: A Theoretical Approach
}

Erotokritos Varelas, (E-mail: varelas@uom.gr), University of Macedonia, Greece Koni Karpeti, (E-mail: karpetikoni@yahoo.com), University of Macedonia, Greece

\begin{abstract}
This paper deals with the way the rate of operational cost, as a proportion of time deposits, affects the optimal level of a monopolistic bank's profits as well as the utility of its clients. In particular we prove that the optimal level of banking profits is negatively related to the rate of operational cost, while changes of the latter affect negatively the time deposit rate and positively the lending rate. As a result of these changes in interest rates, the utility of both borrowers and depositors is proved diminished.
\end{abstract}

\section{INTRODUCTION}

One of the most important factors that affect banking profitability and the levels of lending and time deposit rates is operational cost. H.P. Gray (1964), S.J. Maisel \& R. Jacobson (1978) and M.J. Flannery (1981) have investigated these effects empirically. E. Varelas (2000) has theoretically expressed bank's profitability as a function of the operational cost, $\mathrm{k}$. This paper follows in a quite big extend this theoretical approach and is concerned with the determination of the way the rate of operational cost k, as a proportion of time deposits, $\mathrm{T}$, act upon the optimal level of bank's profits as well as upon the utility of its clients, that is, the depositors and the borrowers.

In particular, after determining the values of deposit $\left(\mathrm{r}_{\tau}^{*}\right)$ and lending $\left(\mathrm{r}_{\ell}^{*}\right)$ rate for which the bank's profits are maximized; we analyze how the optimal level of banking profit is changed because of changes in these interest rates which are generated by changes in the rate of operational cost, k. Following R.J. Barro (1974), we continue our analysis within an overlapping generation context, trying to determine how changes in the rate of operational cost are affecting the depositor's and the borrower's two period optimal level of consumption and consequently their utility. Finally we quote an example, which confirms the arguments that are presented in the theoretical part.

\section{BANKING PROFITS AND THE RATE OF OPERATIONAL COST}

We consider a monopolistic commercial bank, which tries to maximize its profits subject to its budget constrained. The bank's budget constrained results from the asset and liability statement and it has the following form:

$\mathrm{R}+\mathrm{B}+\mathrm{L}=\mathrm{K}+\mathrm{T}$

The left hand side is the assets of the balance sheet and is the sum of reserve requirements, $R$, the money invested in bonds, B and finally the funds loaned to individuals, L. The right hand side is the liabilities of the balance sheet and is the sum of equity capital, $\mathrm{K}$ and the time deposits, $\mathrm{T}$. The level of $\mathrm{R}, \mathrm{L}$ and $\mathrm{T}$ are determined respectively with the help of the following relations: 


$$
\begin{aligned}
& \mathrm{R}=\mathrm{x} \cdot \mathrm{T} \quad, \quad 0<\mathrm{x}<1 \\
& \mathrm{~L}\left(\mathrm{Y}, \mathrm{r}_{\ell}\right)=\alpha_{0} \mathrm{Y}-\alpha_{1} \mathrm{r}_{\ell} \quad, \quad \alpha_{0}>0 \& \alpha_{1}>0 \\
& \mathrm{~T}\left(\mathrm{r}_{\tau}\right)=\tau_{0}+\tau_{1} \mathrm{r}_{\tau} \quad, \quad \tau_{0} \geq 0 \& \tau_{1}>0
\end{aligned}
$$

According to equation (2) the reserve requirements are a fixed portion, $\mathrm{x}$, of time deposits, which is determined exogenously by the Central Bank. Equation (3) states that the loan demand is a positive function of individual's income, $\mathrm{Y}$, and a negative function of the lending rate, $r_{\ell}$. Finally equation (4) describes the time deposit supply by depositors as a positive function of the deposit rate, $r_{\tau}$. It's important to clarify that the bank always accepts the amount of time deposits supplied by individuals and gives as many loans as demanded by borrowers.

Substituting now equation (2), (3) and (4) in equation (1), and rearranging, the new budget constraint can be restated as follows:

$(1-\mathrm{x}) \tau_{1} \mathrm{r}_{\tau}+\alpha_{1} \mathrm{r}_{\ell}=\mathrm{B}-\mathrm{K}-(1-\mathrm{x}) \tau_{0}+\alpha_{0} \mathrm{Y}$

Since we have formulated the budget constraint, we now turn to the construction of the commercial's bank profit function. In general, profits are the difference between revenues and cost. That is

$\Pi=$ Revenue - Cost

The bank's revenue is a sum of the interest received by the funds invested in government bonds, $r_{b} B$, and the interest received by the funds lent to clients, $r_{\ell} L$. The government determines exogenously the rate $r_{b}$ while the bank controls the rate $r_{\ell}$. As far as the cost is concerned, it is the summation of fixed and variable cost. The former is a positive constant magnitude, $\overline{\mathrm{c}}$, while the latter includes the interest paid to depositors, $\mathrm{r}_{\tau} \mathrm{T}$, and the operational cost, which is assumed to be a fixed portion, k, of time deposits, kT. Since the lending and the deposit rate, $\mathrm{r}_{\ell}$ and $r_{\tau}$ respectively, are both controlled by the bank, the mathematical form of the profit function has as follows:

$$
\Pi\left(r_{\ell}, r_{\tau}\right)=\text { Revenue }-\cos t=r_{b} B+r_{\ell} L-\left(r_{\tau}+k\right) T-\bar{c} \underset{(4)}{\stackrel{(3)}{\Rightarrow}}
$$

Equation(7): $\Pi\left(\mathrm{r}_{\ell}, \mathrm{r}_{\tau}\right)=\mathrm{r}_{\mathrm{b}} \mathrm{B}-\left(\overline{\mathrm{c}}+\tau_{0} \mathrm{k}\right)-\alpha_{1} \mathrm{r}_{\ell}^{2}+\alpha_{0} \mathrm{Yr}_{\ell}-\tau_{1} \mathrm{r}_{\tau}^{2}-\left(\tau_{0}+\tau_{1} \mathrm{k}\right) \mathrm{r}_{\tau}$

The profit function is diagrammatically presented in graph 1 as a surface. formal form

What follows from the above analysis is that the maximization problem faced by the bank has the following

$$
\begin{aligned}
& \underset{\mathrm{r}_{\tau}, \mathrm{r}_{\ell}}{\operatorname{Max}} \Pi\left(\mathrm{r}_{\ell}, \mathrm{r}_{\tau}\right)=\mathrm{r}_{\mathrm{b}} \mathrm{B}-\left(\overline{\mathrm{c}}+\tau_{0} \mathrm{k}\right)-\alpha_{1} \mathrm{r}_{\ell}^{2}+\alpha_{0} \mathrm{Yr}_{\ell}-\tau_{1} \mathrm{r}_{\tau}^{2}-\left(\tau_{0}+\tau_{1} \mathrm{k}\right) \mathrm{r}_{\tau} \\
& \text { s.t. } \quad(1-\mathrm{x}) \tau_{1} \mathrm{r}_{\tau}+\alpha_{1} \mathrm{r}_{\ell}=\mathrm{B}-\mathrm{K}-(1-\mathrm{x}) \tau_{0}+\alpha_{0} \mathrm{Y}
\end{aligned}
$$




\section{Graph 1: Diagrammatic representation of the profit function}

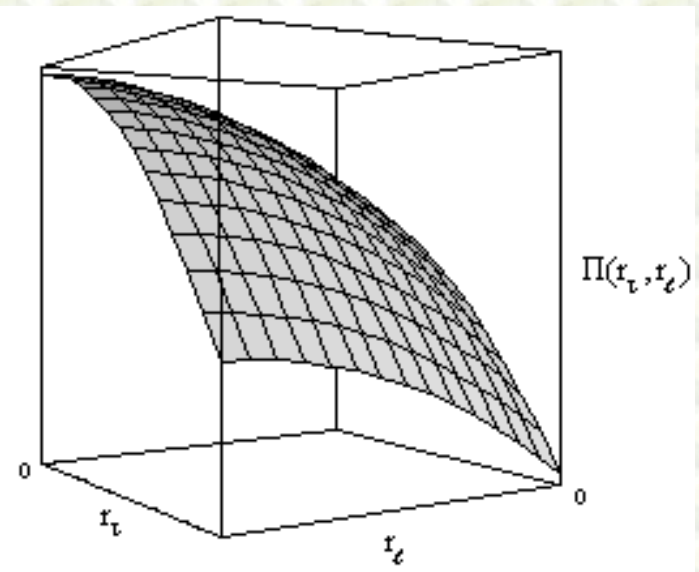

which can be solved by making use of the Lagrangian function

$$
\begin{aligned}
\mathrm{V}\left(\mathrm{r}_{\ell}, \mathrm{r}_{\tau}, \lambda\right)= & \mathrm{r}_{\mathrm{b}} \mathrm{B}-\left(\overline{\mathrm{c}}+\tau_{0} \mathrm{k}\right)-\alpha_{1} \mathrm{r}_{\ell}^{2}+\alpha_{0} \mathrm{Yr}_{\ell}-\tau_{1} \mathrm{r}_{\tau}^{2}-\left(\tau_{0}+\tau_{1} \mathrm{k}\right) \mathrm{r}_{\tau}+ \\
& +\lambda\left[\mathrm{B}-\mathrm{K}-(1-\mathrm{x}) \tau_{0}+\alpha_{0} \mathrm{Y}-(1-\mathrm{x}) \tau_{1} \mathrm{r}_{\tau}-\alpha_{1} \mathrm{r}_{\ell}\right]
\end{aligned}
$$

where $\lambda$ : the Lagrange multiplier

Solving the system that results from the first order maximization conditions ${ }^{1}$ with respect to the endogenous variables $r_{\tau}$ and $r_{\ell}$, we determine the critical point of the maximization problem, which is given directly below

$r_{\tau}^{*}=\frac{2(1-x) \tau_{1}\left[B-K+\alpha_{0} Y / 2-(1-x) \tau_{0}\right]-\alpha_{1}\left(\tau_{0}+\tau_{1} k\right)}{2 \tau_{1}\left[\alpha_{1}+(1-x)^{2} \tau_{1}\right]}$

$\&$

$\mathrm{r}_{\ell}^{*}=\frac{\alpha_{0} \mathrm{Y}}{2 \alpha_{1}}+\frac{\tau_{0}+\tau_{1} \mathrm{k}}{2(1-\mathrm{x}) \tau_{1}}+\frac{2(1-\mathrm{x}) \tau_{1}\left[\mathrm{~B}-\mathrm{K}+\alpha_{0} \mathrm{Y} / 2-(1-\mathrm{x}) \tau_{0}\right]-\alpha_{1}\left(\tau_{0}+\tau_{1} \mathrm{k}\right)}{2 \tau_{1}\left[\alpha_{1}+(1-\mathrm{x})^{2} \tau_{1}\right](1-\mathrm{x})}$

The optimal level of profits results after the substitution of equation (9) and (10) into (7):

$\Pi^{*}\left(\mathrm{r}_{\tau}^{*}, \mathrm{r}_{\ell}^{*}\right)=\mathrm{r}_{\mathrm{b}} \mathrm{B}-\left(\overline{\mathrm{c}}+\tau_{0} \mathrm{k}\right)-\alpha_{1}\left(\mathrm{r}_{\ell}^{*}\right)^{2}+\alpha_{0} \mathrm{Yr}_{\ell}^{*}-\tau_{1}\left(\mathrm{r}_{\tau}^{*}\right)^{2}-\left(\tau_{0}+\tau_{1} \mathrm{k}\right) \mathrm{r}_{\tau}^{*}$

and since the second order condition is satisfied for $\left(\mathrm{r}_{\tau}^{*}, \mathrm{r}_{\ell}^{*}, \lambda^{*}\right)$, equation (11) describes not only the optimum but also the maximum level of profits ${ }^{2}$.

At this point of our analysis arises a crucial question, which has to be answered. How the rate of operational cost, $\mathrm{k}$, affects not only the critical point $\left(\mathrm{r}_{\tau}^{*}, \mathrm{r}_{\ell}^{*}\right)$ but also the magnitude of the maximized profits. In 
order to determine the direction of the relation between $\mathrm{k}$ and $\mathrm{r}_{\tau}^{*}, \mathrm{r}_{\ell}^{*}$, we have to calculate the first partial derivative of $r_{\tau}^{*}$ and $r_{\ell}^{*}$ with respect to $k$. Since

$$
\frac{\partial \mathrm{r}_{\tau}^{*}}{\partial \mathrm{k}}=-\frac{\alpha_{1}}{2\left[\alpha_{1}+(1-\mathrm{x})^{2} \tau_{1}\right]}<0
$$

$\&$

$$
\frac{\partial \mathrm{r}_{\ell}^{*}}{\partial \mathrm{k}}=\frac{(1-\mathrm{x}) \tau_{1}}{2\left[\alpha_{1}+(1-\mathrm{x})^{2} \tau_{1}\right]}>0
$$

we conclude that a raise (fall) of $\mathrm{k}$ leads to a fall (raise) of the deposit rate $\mathrm{r}_{\tau}^{*}$ and to a raise (fall) of the lending rate $\mathrm{r}_{\ell}^{*}$.

Calculating now the total derivative of the profit function with respect to $\mathrm{k}$, we find

$$
\frac{\mathrm{d} \Pi^{*}\left(\mathrm{r}_{\tau}^{*}, \mathrm{r}_{\ell}^{*}\right)}{\mathrm{dk}}=-\left(\tau_{0}+\tau_{1} \mathrm{r}_{\tau}^{*}\right)<0
$$

According to equation (14), a change in operational cost by $\mathrm{dk}$ affects negatively the magnitude of the maximum profits, i.e. a raise in $\mathrm{k}$ by $\mathrm{dk}$ causes a fall of maximum profits by $-\left(\tau_{0}+\tau_{1} \mathrm{r}_{\tau}^{*}\right) \mathrm{dk}$.

\section{UTILITY AND THE RATE OF OPERATIONAL COST}

The traditional role of the bank, among other things, is the intermediary between the depositor and the borrower. Each one is willing to lend or borrow in order to maximize his utility, which has the following functional form

$\mathrm{U}\left(\mathrm{c}_{1}, \mathrm{c}_{2}\right)=\mathrm{c}_{1}^{\mathrm{z}} \mathrm{c}_{2}^{1-\mathrm{z}} \quad, 0<\mathrm{z}<1$

where $z= \begin{cases}a, & \text { in the case of the depositor } \\ b, & \text { in the case of the borrower }\end{cases}$

Either the depositor or the borrower must take into consideration his budget constraint before trying to maximize his utility. In order to formulate the budget constraint for each one, we assume firstly that the lifetime span is extended in two periods. Secondly that the depositor does not inherit or bequeath any amount of money and he can invest only in time deposits. On the other hand the borrower does not inherit or leave any debt and he does not save any amount of money. We also assume that time deposits can be made only in the beginning of the first period and the depositor withdraws the initial capital increased by interest at the beginning of the second period. Accordingly the borrower raises a loan at the first period of his lifetime and the full repayment of the loan increased by interest is made at the beginning of the second period. The final assumption concerns the price level of consumer goods, which is considered constant in time. 

relations

Therefore we can express the budget constraint for the borrower and the depositor with the following

$\mathrm{g}\left(\mathrm{c}_{1}, \mathrm{c}_{2}\right)=(1+\mathrm{w}) \mathrm{c}_{1}+\mathrm{c}_{2}=(1+\mathrm{w}) \mathrm{y}_{1}+\mathrm{y}_{2}$

where $\mathrm{w}= \begin{cases}\mathrm{r}_{\tau}^{*}, & \text { in thecase of the depositor } \\ \mathrm{r}_{\ell}^{*}, & \text { in the case of the borrower }\end{cases}$

We continue our analysis with the formulation of the maximization problem faced by the borrower and the depositor, which results from the combination of equations (15) and (16). That is

$$
\underset{\mathrm{c}_{1}, \mathrm{c}_{2}}{\operatorname{Max}} \mathrm{U}\left(\mathrm{c}_{1}, \mathrm{c}_{2}\right)=\mathrm{c}_{1}^{\mathrm{z}} \mathrm{c}_{2}^{1-\mathrm{z}}
$$

s.t. $\mathrm{g}\left(\mathrm{c}_{1}, \mathrm{c}_{2}\right)=(1+\mathrm{w}) \mathrm{c}_{1}+\mathrm{c}_{2}=(1+\mathrm{w}) \mathrm{y}_{1}+\mathrm{y}_{2}$

which can be solved using the Lagrangian function

$Q\left(c_{1}, c_{2}, q\right)=c_{1}^{z} c_{2}^{1-z}+q\left[(1+w)\left(y_{1}-c_{1}\right)+y_{2}-c_{2}\right]$

Solving the system of the first order condition ${ }^{3}$ with the respect to endogenous variables $c_{1}$ and $c_{2}$, we are in a position to determine the critical point of the maximization problem. The optimal level of consumption for the first and the second period respectively is

$$
\mathrm{c}_{1}^{*}=\mathrm{zy}_{1}+\frac{\mathrm{z}}{1+\mathrm{w}} \mathrm{y}_{2}
$$

\&

$\mathrm{c}_{2}^{*}=(1-\mathrm{z})\left[(1+\mathrm{w}) \mathrm{y}_{1}+\mathrm{y}_{2}\right]$

The point $\left(\mathrm{c}_{1}^{*}, \mathrm{c}_{2}^{*}\right)$ is not only the optimal but is also the maximum since the second order condition ${ }^{4}$ is satisfied for $\left(c_{1}^{*}, c_{2}^{*}, q^{*}\right)$.

Next we are going to prove how the maximum levels of $c_{1}^{*}$ and $c_{2}^{*}$, and therefore the utility as of the depositor as of the borrower, are affected by the rate of operational cost $k$. In order to demonstrate how a change of $\mathrm{k}$ causes a change in $\mathrm{c}_{1}^{*}$ and $\mathrm{c}_{2}^{*}$, we have to calculate the partial derivative of $\mathrm{c}_{1}^{*}$ and $\mathrm{c}_{2}^{*}$ with respect to $\mathrm{k}$ from equation (18) and (19) respectively.

$$
\frac{\partial \mathrm{c}_{1}^{*}}{\partial \mathrm{k}}=(-1)^{\mathrm{i}} \frac{\mathrm{y}_{2}}{(1+\mathrm{w})^{2}} \cdot \frac{\varphi}{2\left[\alpha_{1}+(1-\mathrm{x})^{2} \tau_{1}\right]}
$$

\&

$$
\frac{\partial c_{2}^{*}}{\partial k}=(-1)^{j}(1-z) y_{1} \frac{\varphi}{2\left[\alpha_{1}+(1-x)^{2} \tau_{1}\right]}
$$


where $\varphi=\alpha_{1}, i=2$ and $j=1$ in the case of the depositor and

$\varphi=(1-x) \tau_{1}, i=1$ and $j=2$ in the case of the borrower

But what are the signs of $\partial \mathrm{c}_{1}^{*} / \partial \mathrm{k}$ and $\partial \mathrm{c}_{2}^{*} / \partial \mathrm{k}$ ? In the case of the depositor the former is positive and the latter is negative. The opposite is held in the case of the borrower. What is most interesting though is in what way the total level of consumption, and consequently the utility, is affected by parameter $\mathrm{k}$. In order to analyze this subject, we will calculate the total derivative of the first order conditions treating $\mathrm{dq}^{*}, \mathrm{dc}_{1}^{*}$ and $\mathrm{dc}_{2}^{*}$ as endogenous variables. The following equations result from the calculation.

$$
\begin{aligned}
& \frac{\mathrm{dc}_{1}}{\mathrm{dw}}=\frac{\left|\mathrm{B}_{12}\right|}{|\mathrm{B}|}\left(\mathrm{c}_{1}-\mathrm{y}_{1}\right)+\frac{\left|\mathrm{B}_{22}\right|}{|\mathrm{B}|} \mathrm{q} \\
& \frac{\mathrm{dc}_{2}}{\mathrm{dw}}=\frac{\left|\mathrm{B}_{13}\right|}{|\mathrm{B}|}\left(\mathrm{c}_{1}-\mathrm{y}_{1}\right)+\frac{\left|\mathrm{B}_{23}\right|}{|\mathrm{B}|} \mathrm{q} \\
& \frac{\mathrm{dq}}{\mathrm{dw}}=\frac{\left|\mathrm{B}_{11}\right|}{|\mathrm{B}|}\left(\mathrm{c}_{1}-\mathrm{y}_{1}\right)+\frac{\left|\mathrm{B}_{21}\right|}{|\mathrm{B}|} \mathrm{q}
\end{aligned}
$$

where $|\mathrm{B}|=\left|\overline{\mathrm{D}}\left(\mathrm{c}_{1}^{*}, \mathrm{c}_{2}^{*}, \mathrm{q}^{*}\right)\right|:$ the border Hessian determinant

$\left|\mathrm{B}_{\mathrm{ij}}\right|$ : the product of $(-1)^{\mathrm{i}+\mathrm{j}}$ by the determinant that arises from the border Hessian determinant if we abstract the $i$ row and the $\mathrm{j}$ column

From equation (22) and (23) results that a change in consumption because of a change in the lending and deposit rates is the sum of two magnitudes, the income and the substitution effect. After proper calculations we conclude that the substitution effect can be stated for the two time periods as follows

$$
\left.\mathrm{dc}_{1}\right|_{\mathrm{u}=\overline{\mathrm{u}}}=\frac{\left|\mathrm{B}_{22}\right|}{|\mathrm{B}|} \mathrm{qdw}
$$

$\&$

$\left.\mathrm{dc}_{2}\right|_{\mathrm{u}=\overline{\mathrm{u}}}=\frac{\left|\mathrm{B}_{23}\right|}{|\mathrm{B}|} \mathrm{qdw}$

while the income effect is given by

$1^{\text {st }}$ period: $\frac{\left|B_{12}\right|}{|B|}\left(c_{1}-y_{1}\right) d w$

$2^{\text {nd }}$ period: $\frac{\left|B_{13}\right|}{|B|}\left(c_{1}-y_{1}\right) d w$

$\&$ 
Our analysis will be completed if we determine the signs of the income and the substitution effect for each period and each individual. The following table presents the calculated results

Table 1: Income and Substitution Effects

\begin{tabular}{|l|c|c|c|c|}
\hline & $\left.\mathrm{dc}_{1}\right|_{\mathrm{u}=\overline{\mathrm{u}}}$ & $\begin{array}{c}1^{\mathrm{st}} \text { period's income } \\
\text { effect }\end{array}$ & $\left.\mathrm{dc}_{2}\right|_{\mathrm{u}=\overline{\mathrm{u}}}$ & $\begin{array}{c}2^{\text {nd }} \text { period's income } \\
\text { effect }\end{array}$ \\
\hline Depositor & + & - & - & - \\
Borrower & - & - & + & - \\
\hline
\end{tabular}

As far as the depositor is concerned, the final conclusion is that the level of the first period's consumption is affected positively by changes in the deposit rate only if the positive substitution effect is greater than the negative income effect in absolute values while the level of the second period's consumption is affected negatively. The opposite is held in the case of the borrower.

The question is how the individual's (i.e. the depositor and the borrower) utility is affected. The answer to this question is given via the following graphs.

\section{Graph 2: The income and substitution effects in the case of the depositor [Graph (A)] and the borrower [Graph (B)].}

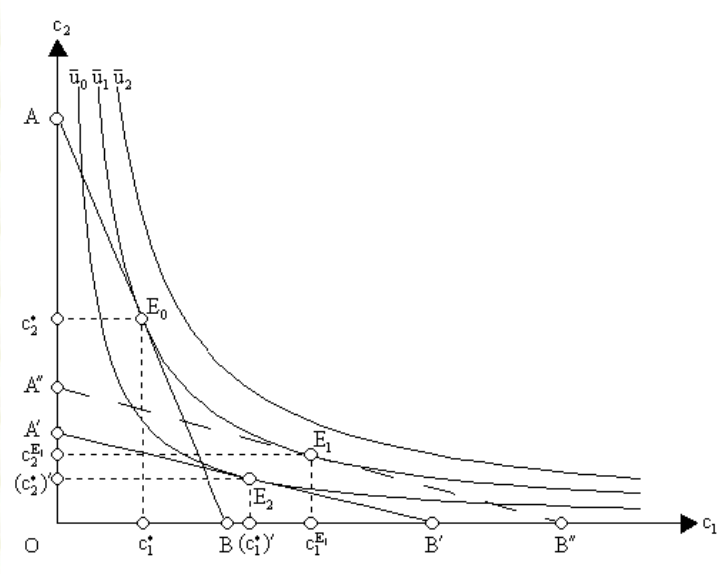

(A)

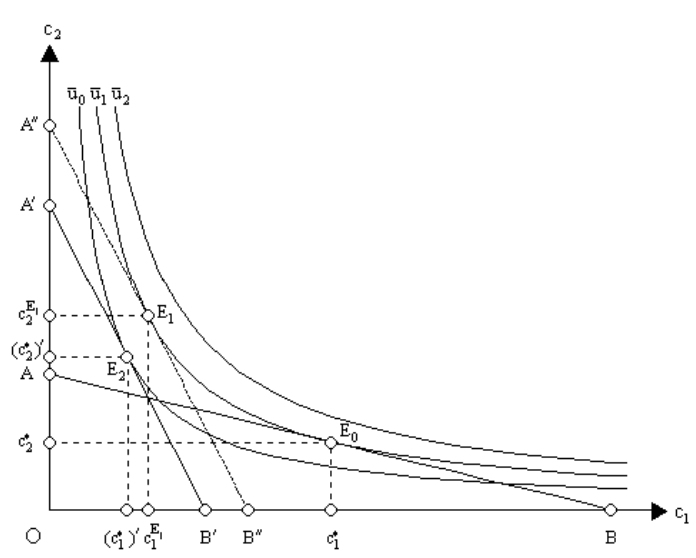

(B)

The final conclusion is that both the depositor and the borrower are forced to balance in a lower indifference curve (i.e. $\mathrm{u}_{0}<\mathrm{u}_{1}$ ). That is their utility is decreased because of changes in lending and deposit rates after the increase in the rate of operational cost.

\section{AN EXAMPLE}

In order to prove that the arguments in the theoretical part of our analysis are held we illustrate a numerical example. In particular, we assume that the bank's assets and liabilities are as follows: $\mathrm{R}=\quad=20, \mathrm{~B}=816, \mathrm{~L}=164$ (therefore $\mathrm{R}+\mathrm{B}+\mathrm{L}=1000$ ) and $\mathrm{K}=800, \mathrm{~T}=200$ (that is $\mathrm{K}+\mathrm{T}=1000$ ). Consequently from equation (2), we find that $\mathrm{x}=10 \%$. Moreover we assume that the loan demand and time deposits supply functions ${ }^{5}$ are $\mathrm{L}\left(\mathrm{Y}, \mathrm{r}_{\ell}\right)=100-1000 \mathrm{r}_{\ell}$ and $\mathrm{T}\left(\mathrm{r}_{\tau}\right)=2000 \mathrm{r}_{\tau}$ respectively. We consider the rate of operational cost to be $1.4 \%$ (or 0.014 ) and the fixed cost of the bank is 40 . Finally the Central Bank has defined the rate of bonds to be $6 \%$. Accordingly the maximization problem that the bank faces is 
$\operatorname{Max} \Pi\left(\mathrm{r}_{\tau}, \mathrm{r}_{\ell}\right)=8.96-1000 \mathrm{r}_{\ell}^{2}+100 \mathrm{r}_{\ell}-2000 \mathrm{r}_{\tau}^{2}-28 \mathrm{r}_{\tau}$ $\mathrm{r}_{\tau}, \mathrm{r}_{\ell}$

$$
\text { s.t. } 1000 \mathrm{r}_{\ell}+1800 \mathrm{r}_{\tau}=116
$$

The solution of this problem results to the level of the time deposit and lending rate for which the profit function is maximized, namely $r_{\tau}^{*}=2 \%$ and $r_{\ell}^{*}=8 \%$. Substituting them into the profit function we calculate the optimal level of profits, i.e. $\Pi^{*}\left(\mathrm{r}_{\tau}^{*}, \mathrm{r}_{\ell}^{*}\right)=9.2$.

According to equations (12) and (13) a change in $\mathrm{k}$ affects negatively the optimal level of time deposit and positively this of lending rate. This argument is confirmed since if we double $\mathrm{k}$, i.e. $\mathrm{k}^{\prime}=\quad=2.8 \%$, then $\left(\mathrm{r}_{\tau}^{*}\right)^{\prime}=1.73 \%$ and $\left(\mathrm{r}_{\ell}^{*}\right)^{\prime}=8.48 \%$. The argument based on equation (14), that a raise in $\mathrm{k}$ results to a fall of the optimal level of profits, is also confirmed since $\mathrm{d} \Pi^{*}(\cdot)=-0.56$.

Next we examine how a shift in parameter $\mathrm{k}$ affects the depositor's and the borrower's utility. The following table cites the assumptions that concern the individuals.

Table 2: Depositor's \& Borrower's Data

\begin{tabular}{|c|c|c|c|c|c|c|}
\hline \multirow{2}{*}{ 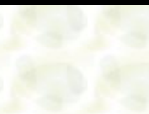 } & \multirow{2}{*}{ Utility Function } & \multicolumn{2}{|c|}{ Income } & \multirow{2}{*}{ Budget Constraint } & \multirow{2}{*}{$\mathrm{r}_{\tau}^{*}$} & \multirow{2}{*}{$\mathrm{r}_{\ell}^{*}$} \\
\hline & & $\mathrm{y}_{1}$ & $\mathrm{y}_{2}$ & & & \\
\hline Depositor & $\mathrm{U}\left(\mathrm{c}_{1}, \mathrm{c}_{2}\right)=\mathrm{c}_{1}^{1 / 4} \mathrm{c}_{2}^{3 / 4}$ & 100 & 150 & $1.02 \mathrm{c}_{1}+\mathrm{c}_{2}=252$ & $2 \%$ & - \\
\hline Borrower & $\mathrm{U}\left(\mathrm{c}_{1}, \mathrm{c}_{2}\right)=\mathrm{c}_{1}^{3 / 4} \mathrm{c}_{2}^{1 / 4}$ & 150 & 100 & $1.08 \mathrm{c}_{1}+\mathrm{c}_{2}=262$ & - & $8 \%$ \\
\hline
\end{tabular}

Therefore the critical point $\left(c_{1}^{*}, c_{2}^{*}\right)$ is $(61.77,189)$ and $(181.94,65.5)$ for the depositor and the borrower respectively. But the optimal levels of the first and the second period's consumption are altered because of changes in $r_{\tau}^{*}$ and $r_{\ell}^{*}$. In particular, as far as the depositor is concerned, holds $\mathrm{dc}_{1}=0.096$ and $\mathrm{dc}_{2}=-0.200$. In the case of the borrower the equivalent magnitudes are -0.309 and 0.180 . These results confirm the hold of equation (20) and (21). Of course we argued that the total shift in consumption of the first and second period is the summation of the income and substitution effects which are presented in the following table:

Table 3: Income \& Substitution Effects for $\left(c_{1}^{*}, c_{2}^{*}\right)$

\begin{tabular}{|c|c|c|}
\hline & Depositor & Borrower \\
\hline $\begin{array}{c}\left.\mathrm{dc}_{1}\right|_{\mathrm{u}=\overline{\mathrm{u}}} \\
1^{\mathrm{st}} \text { period's } \\
\text { income effect }\end{array}$ & 0.121 & -0.202 \\
\hline Total & -0.025 & -0.107 \\
\hline $\begin{array}{c}\left.\mathrm{dc}\right|_{\mathrm{u}=\overline{\mathrm{u}}} ^{\text {nd }} \text { period's } \\
\text { income effect }\end{array}$ & 0.096 & 0.218 \\
\hline Total & -0.124 & -0.038 \\
\hline
\end{tabular}




\section{CONCLUSIONS}

In this paper we analyzed how the profits of a commercial bank are affected by the rate of operational cost $\mathrm{k}$. After we specified the bank's profit function, we determined the optimal level of the time deposit and lending rates, which maximize the bank's profits. Next we proved that the bank alters the level of the time deposit and lending rates because of changes in parameter $\mathrm{k}$. As a result the level of profits is fallen.

The shift of k influences not only banking profits but also the utility of the borrower and depositor. Initially we formulated the utility maximization problem for both of them in order to find the optimal level of consumption for each period of their time horizon. Afterwards we determined how the rate of operational cost affects these levels. We reached to the conclusion that a raise (fall) in $\mathrm{k}$ results in a fall (raise) of time deposit rate and in a raise (fall) of lending rate. In turn these shifts lead to further changes of the consumption levels either for depositor or the borrower. In particular, as far as the first period of their lifetime is concerned, a raise (fall) in depositor's consumption and a fall (raise) in borrower's consumption have occurred. On the other hand, depositor's second period consumption is fallen (raised) while borrower's is raised (fallen). As a result the utility of both the depositor and the borrower is diminished.

\section{ENDNOTES}

1. $\quad$ Namely $\partial \mathrm{V}(\cdot) / \partial \mathrm{r}_{\tau}=-2 \tau_{1} \mathrm{r}_{\tau}-\left(\tau_{0}+\tau_{1} \mathrm{k}\right)-\lambda(1-\mathrm{x}) \tau_{1}=0, \quad \partial \mathrm{V}(\cdot) / \partial \mathrm{r}_{\ell}=-2 \alpha_{1} \mathrm{r}_{\ell}+\alpha_{0} \mathrm{Y}-\lambda \alpha_{1}=0 \quad \&$ $\partial \mathrm{V}(\cdot) / \partial \lambda=\mathrm{B}-\mathrm{K}-(1-\mathrm{x}) \tau_{0}+\alpha_{0} \mathrm{Y}-(1-\mathrm{x}) \tau_{1} \mathrm{r}_{\tau}-\alpha_{1} \mathrm{r}_{\ell}=0$.

2. The second order condition is satisfied for $\left(\mathrm{r}_{\tau}^{*}, \mathrm{r}_{\ell}^{*}, \lambda^{*}\right)$ since the border Hessian determinant is positive, i.e. $\left|\overline{\mathrm{H}}\left(\mathrm{r}_{\tau}^{*}, \mathrm{r}_{\ell}^{*}, \lambda^{*}\right)\right|=2 \alpha_{1} \tau_{1}\left[2 \alpha_{1}+(1-\mathrm{x})^{2} \tau_{1}\right]>0$.

3. That is $\frac{\partial \mathrm{Q}(\cdot)}{\partial \mathrm{c}_{1}}=\mathrm{z}\left(\frac{\mathrm{c}_{2}}{\mathrm{c}_{1}}\right)^{\mathrm{z}-1}-\mathrm{q}(1+\mathrm{w})=0, \frac{\partial \mathrm{Q}(\cdot)}{\partial \mathrm{c}_{2}}=(\mathrm{z}-1)\left(\frac{\mathrm{c}_{2}}{\mathrm{c}_{1}}\right)^{-\mathrm{z}}-\mathrm{q}=0, \frac{\partial \mathrm{Q}(\cdot)}{\partial \mathrm{q}}=(1+\mathrm{w})\left(\mathrm{y}_{1}-\mathrm{c}_{1}\right)+\mathrm{y}_{2}-\mathrm{c}_{2}=0$

4. The second order condition is held for $\left(\mathrm{c}_{1}^{*}, \mathrm{c}_{2}^{*}, \mathrm{q}^{*}\right)$ since the border Hessian determinant is positive, i.e. $\left|\overline{\mathrm{D}}\left(\mathrm{c}_{1}^{*}, \mathrm{c}_{2}^{*}, \mathrm{q}^{*}\right)\right|=(1+\mathrm{w}) \mathrm{z}(1-\mathrm{z})\left(\mathrm{c}_{2} / \mathrm{c}_{1}\right)^{-\mathrm{z}}\left[(1+\mathrm{w}) \mathrm{c}_{2}^{-1}+2 \mathrm{c}_{1}^{-1}+\mathrm{c}_{2} \mathrm{c}_{1}^{-2}(1+\mathrm{w})^{-1}\right]>0$.

5. It is obvious that $\alpha_{0} \mathrm{Y}=100, \alpha_{1}=1000, \tau_{0}=0$ and $\tau_{1}=2000$.

\section{REFERENCES}

1. Barro, R.J., “Are Government Bonds Net Wealth?”, The Journal of Political Economy, Vol. 82 , No 6, p.p. 1095 - 1117, 1974.

2. Barro, R.J., "The Ricardian Approach to Budget Deficits", The Journal of Economic Perspectives, Vol. 3, No 2 , p.p. $37-54,1989$.

3. Barro, R.J., Macroeconomics, $5^{\text {th }}$ edition, The MIT Press Cambridge, Massachusetts London, England, 1997.

4. Birdsall, W.C. \& Goldstein, J.H., "The Effect of Interest - Rate Changes on Consumption Allocation Over Time", International Economic Review, Vol. 14, No 2, pp. 487 - 792, 1973.

5. Blanchard, O.J., "Debt, Deficits and Finite Horizons", The Journal of Political Economy, Vol. 93, No 2, p.p. $223-247,1985$.

6. Chiang, A.C., Fundamental Methods of Mathematical Economics, $3^{\text {rd }}$ edition, McGraw-Hill International Editions, 1984.

7. Flannery, M.J., "Market Interest Rates and Commercial Bank Profitability: An Empirical Investigation", The Journal of Finance, Vol. 36, No 5, p.p. 1085 - 1101, 1981.

8. Goldfeld, S.M. \& Jaffee, D.M., "The Determinants of Deposit-Rate Setting by Savings and Loan Associations", The Journal of Finance, Vol.25, No 3, p.p. 615 - 632, 1970. 
9. Gray, P.H., "Some Evidence on Two Implications of Higher Interest-Rates on Time Deposits", The Journal of Finance, Vol.19, No 1, p.p. 63 - 75, 1964.

10. Henderson, J.M. \& Quandt, R.E., Microeconomic Theory - A Mathematical Approach, $3^{\text {rd }}$ edition, McGraw-Hill International Editions, 1980.

11. Karatzas, I. \& Shreve, S.E., Methods of Mathematical Finance, Springer - Verlag, New York, 1998.

12. Maisel, S.J. \& Jacobson, R., "Interest Rate Changes and Commercial Bank Revenues and Costs", The Journal of Financial and Quantitative Analysis, Vol. 13, No 4, p.p. 687 - 700, 1978.

13. Romer, D., Advanced Macroeconomics, McGraw-Hill, 1996.

14. Seater, J.J., "Ricardian Equivalence", Journal of Economic Literature, Vol.31, No 1, p.p. 142 - 190, 1993.

15. Varelas, E., Special Issues in Monetary Theory, (in Greek), Benos Publications, Athens, 2000. 